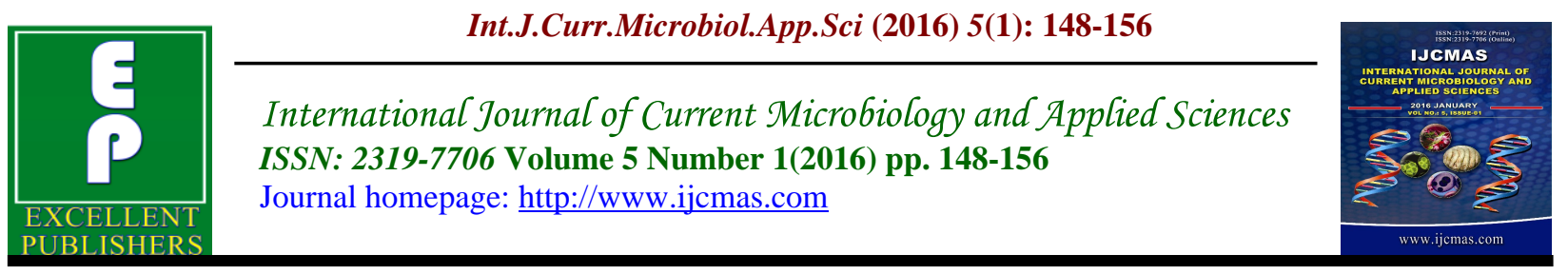

Review Article

doi: hittp://dx.doi.org/10.20 $0 \overline{4} 46 /$ ijcmas.2016.501.012

\title{
Sustainable Agriculture: A Key to the Healthy Food and Better Environment, Economic Prosperity for Farmers and a Step towards Sustainable Development
}

\author{
Bhupinder Singh ${ }^{1 *}$ and Lalit Jajpura ${ }^{2}$ \\ ${ }^{1}$ Department of Basic and Applied Sciences, Bhagat Phool Singh Mahila Vishwavidyalaya, \\ Khanpur Kalan, Sonepat, Haryana, India \\ ${ }^{2}$ Department of Fashion Technology, Bhagat Phool Singh Mahila Vishwavidyalaya, Khanpur \\ Kalan, Sonepat, Haryana, India \\ *Corresponding author
}

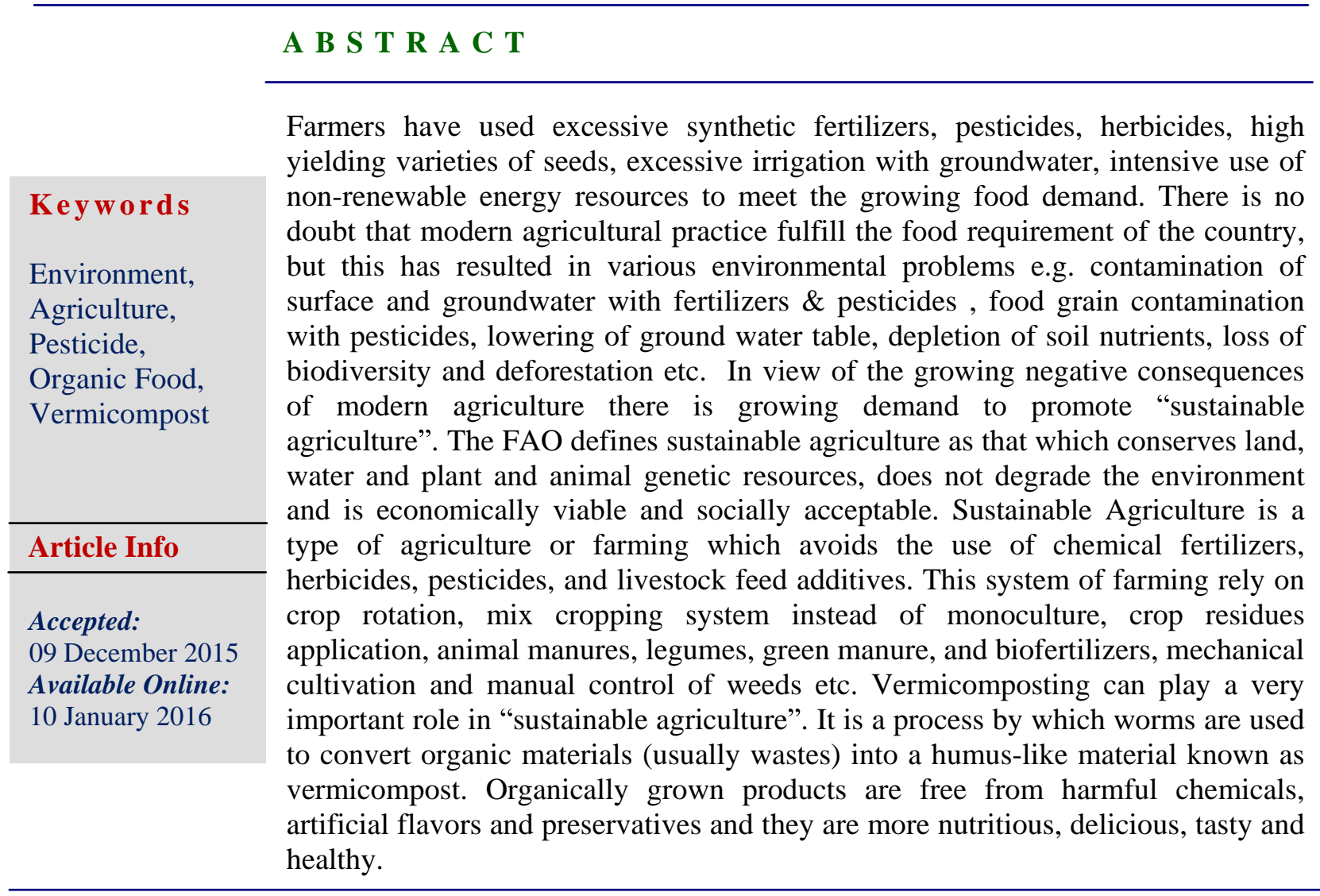

\section{Introduction}

Human beings started the practice of agriculture perhaps 10000-12000 years ago. It is the art and science of crop and livestock production. The word 'Agriculture' is combination of two latin words: Agri (field), and cultura (cultivation), which means 
tillage of soil to cultivate the crops. It is well known fact that around $70 \%$ of the population in India earns its livelihood from agriculture. After the implementation of green revolution farmers have contributed remarkably in achieving self-sufficiency in food production of the nation. It is estimated that in 2012-2013, approximate food grains production in India was 250 million tones. The indiscriminate uses of synthetic fertilizers and chemicals pesticide polluted our environment. However due intensive agriculture the water table has gone down in various parts of the country. Pest problem is still persisting in different crops. Soil fertility is deteriorating day by day. A number of health hazards have been identified in animals and human beings.

Pesticide poisoning among farmers and occupational workers in developing countries is alarming (McCauley et al., 2006) and It is a major public health problem in many developing countries (Jeyaratnam, 1990; Hashmi \& Dilshad, 2011). WHO estimated approximately 20,000 workers die from exposure every year, the majority in developing countries (Pimentel et al., 1992; Kishi et al., 1995). Indian farmer is using wide ranges of chemical pesticides to limit the losses from pests and diseases, in which insecticides account for 73 per cent, herbicides 14 per cent, fungicides 11 per cent and others 2 per cent (Grace, et al., 2007). Chemical pesticide use is associated with risk and health hazards if not handled properly. Improper handling and unsafe spraying of the agrochemicals cause high risk of health hazards reported in the past studies (Gupta, 2004). Centre for Science and Environment (CSE) reported that pesticide exposure causes acute poisoning, cancer and neurological impairment, reproductive and developmental problems (Arora, 2007, Takagi, et al., 1997).
Chemical fertilizers are the immediate source of nutrients in soils. Consumption of nitrogenous $(\mathrm{N})$, phosphatic $(\mathrm{P})$ potassic $(\mathrm{K})$ fertilizers have increased from 1.1 million tonnes in 1966-67, the year preceding the green revolution to 27.7 million tonnes in 2011-12. The all-India average consumption of fertilizers has increased from $105.5 \mathrm{~kg}$ per ha in 2005-06 to $144 \mathrm{~kg}$ per ha in 2011-12. Intensive use of macro nutrients in the soil is experiencing widespread deficiency of micronutrients particularly of Zinc followed by Iron, Manganese, Boron, etc. Further, excessive uses of synthetic fertilizers adversely affect the soil health e.g. soil in various part of the Punjab affected (12). Beside this, when the rate of nitrogenous $(\mathrm{N})$ fertilizer application exceeds the plant demand and denitrifying capacity of soil, the fertilizer percolates down to groundwater in the form of nitrate through the soil profile and contaminates it. Nitrate above $45 \mathrm{mg} / \mathrm{l}$ can cause methemoglobinemia (commonly known as blue baby syndrome) and intestinal cancer (WHO 1985). The nitrate content in the groundwater of Punjab and Haryana is presented in Table 1.

It is evident from the above discussion that modern agriculture has a lot of ill effects so, it forced people in different parts of the world to demand food grown without fertilizer and pesticides and this give rise to the concept of sustainable agriculture.

\section{Sustainable Agriculture}

Intensive agricultural activities give rise to various problems e.g. soil pollution, land degradation, loss of biodiversity, contamination of water resources, pesticide residue problem, depletion of groundwater and impacts on human health etc. So, what is the solution? The answer is sustainable agriculture. It is a form of agriculture which aims to produce enough food to meet the 
needs of present day generation without deteriorating soil fertility and irreversibly damaging the environment. Sustainable agriculture practice are those that are least toxic and least energy intensive and yet maintain productivity and profitability i.e. low input agriculture or organic farming. Thus sustainable agriculture is that which-

- Maintain the soil fertility,

- Do not use of chemical pesticide;

- Uses natural resources efficiently;

- Improve over all environmental quality;

- Less use of non renewable natural resources;

- Provides safe and healthy agricultural products;

- Improve the life of rural communities and farmers;

- Uses the natural resources as per their carrying capacity;

- Above all it save the natural resources for next generations.

Methods used to achieve Sustainable Agriculture

The sustainable agriculture depends upon various factors e.g. topography of the area, type of soil, availability of water, type of crop and seeds, climate of the area and above all goal of the farmers. Different methods involved in sustainable agriculture are:

- Cultivation practices to enhance the natural and financial stability.

- Selection of varieties as per need and environmental conditions.

- Management of soil fertility by using appropriate tillage method

- Using the practice of integrated pest management.

- Integrated Nutrients Management

Actually this is the practice of agriculture which was in use before 1950s in various developing countries including India. In other word this is the traditional form of agriculture wherein farmers follow the practice of mixed cropping and crop rotation. The different techniques which can be used to achieve sustainable agriculture are:

\section{(a) Mixed Cropping}

It is old agricultural technique and here two or more crops are grown together on the same plot of land at a time. The crops grown have different water and nutrients requirement. They also have different maturity time. If by chance one crop destroyed, the others crops cover the risk of total crop failure. Generally, a long duration crop is grown along with a short duration crop so that both the crops get sufficient nutrients and water. Generally a leguminous crop is grown along with the main crop. Leguminous crops improve soil fertility by fixing atmospheric nitrogen. This not only save the cost of chemical fertilizers but also prevent the ground water from nitrate contamination. The various strategies involved in mixed cropping are:

- Different cultivars of the same crop are grown at a time on a same plot of land.

- Intercropping where two or more crops are grown e.g. cereal that uses soil nitrogen and nitrogen fixing legume that fix the nitrogen in the soil.

- Polyculture, in which different plants maturing at different times are grown together.

This practice is very beneficial because nutrient and water requirement of crops grown are different so there is less need of these inputs and soil restores nutrients 
naturally. In monoculture farmers sow only one type of crop e.g. wheat and rice which uses excessive chemical fertilizers, water and pesticides and causes environmental and economic problems.

\section{(b) Crop Rotation}

Here different crops are grown in regular succession on the same plot of land. Actually it helps in control of diseases \& pests restore soil fertility and control soil erosion. Actually soil cannot sustain high yielding varieties continuously because of their high nutrient requirement. The farmers supply only macronutrients i.e. NPK to these high yielding varieties and ignore the micronutrients e.g. zinc and boron etc. and give rise to the problem of micronutrient imbalance. In crop rotation leguminous crop are grown after the main crop. Leguminous crops improve soil fertility by fixing atmospheric nitrogen. This not only save the cost of chemical fertilizers but also prevent the ground water from nitrate contamination. Beside this, this practice also controls the pest \& diseases as different crops have different types of pest and their natural predators. Farmers not only grow food crops in this practice but also grow fodder for livestock which prevent soil erosion. This practice of cultivation considers the following factors for better output:

- Leguminous crop should be grown after the main crop to replenish the nitrogen content of the soil.

- Less irrigation requiring crop should be grown after the more irrigation requiring crop.

Crops requiring fewer nutrients should be grown after one that requires more nutrients.

Adopting these practices of cultivation can improve the soil as well as food quality e.g. Green gram - Wheat - Moong crop pattern can be used to improve the soil and environmental health.

\section{Soil Management}

Fertile and healthy soil is one of the most important parameter for sustainable agriculture. The good soil produces good produce and that is less prone to pest attack so there is lee or no need of pesticides. Therefore the quality of soil should be improved for better results. The nutrient quality of soil can be improved by applying traditional manure e.g. by using compost, vermicompost, reducing tillage and conserving soil moisture by using agricultural residues. This not only increases nutrient content of the soil but also increases water hold capacity of the soil. No till agriculture is also a promising technique to conserve the soil nutrients.

Soil Organic Carbon (SOC) is central to soil health due to its influence on soil structure, water retention, microbial activities, soil aeration, and nutrient retention. It is the organic forms of $\mathrm{C}$ and not the source of nutrient which is important for soil-plant continuum. To conserve the quality of soil farmers should be provided with improved varieties of food grains, fodder, sugar, oil, fibers, fruits and vegetables. This can be achieved by the application of plant breeding and genetic engineering from existing varieties of crop cultivars. These improved varieties of crops should be:

- disease and pest resistant;

- have better nutritional value;

- require less water for irrigation;

- require less nutrients application;

- Resistant to drought, heat, cold and frost etc. 


\section{Bio-fertilizers in Sustainable Agriculture}

To enhance the growth and yield of crops, plants require optimum amount of nutrients, sufficient water for irrigation and protection from pest. As we have seen that synthetic fertilizers, excessive use of water and pesticides causes various environmental problems. The table: 2 show the pattern of consumption of different types of fertilizers in India from 1991 to 2012.

Agriculture and Cooperation, Directorate of Economics and Statistics, New Delhi

One of the ways to overcome the problem of synthetic fertilizers is the use of certain strain of bacteria, algae and fungi to fix atmospheric nitrogen, convert phosphorus in to soluble form, decompose organic material and oxidize sulphur in the soil. They improve the soil fertility \& crop quality, enhance the yield and may control the pollution. These are known as "bio fertilizers". Hence bio-fertilizers are living and biologically active and they improve soil quality naturally. Some of the important bio-fertilizers are: Rhizobium, Azobacter, Azospirillium, Blue green algae or cynobacteria and Azolla etc.

\section{Role of Organic Farming in Sustainable Agriculture}

It is a form of cultivation where farmers do not use synthetic fertilizers, pesticides and growth hormones. The foods grown organically are free from contamination, tasty, better aroma and have no pesticide residues. Here traditional methods of cultivation e.g. Crop rotation, crop residues, animal manures, legumes, green manure, off-farm organic wastes and bio-fertilizers are used. To control pest, integrated pest management practice is adopted. To control weeds, crop rotation and manual methods are used. However, the cost of organically produced food is higher than the food produced by commercial methods but quality of food grown organically is nutritious and healthy. As farmers do not use synthetic fertilizers so, the yield of crop is less. The people conscious about the health, prefer organic food instead of higher cost. Further, for small farmers it is a profitable farming practice as it cut the cost of synthetic fertilizers and pesticides and the cost of their product is more. Organic farming practice is not only beneficial for human beings but it is also beneficial for micro-organisms, earthworms, wildlife and over all for the environment.

\section{Role of Vermicomposting in Sustainable Agriculture}

Vermicomposting has been considered to be an advantageous technique to improve the soil health. It has been established that maintenance of ecological balance for sustainable agriculture an alternative to chemical agriculture is use of vermicompost (Harris et al., 1990).Vermicompost, is the heterogeneous mixture of decomposing fraction of waste, bedding materials, and cocoons, hatching etc. produced during the course of normal vermiculture operations. The process of producing vermicompost is called vermicomposting. The agricultural residues, organic waste, kitchen waste, poultry waste, grass clippings, dairy waste etc can be used as a feed stock for earthworms in the process of vermicomposting.

In tropical countries due to high temperature and low moisture, the use of inorganic fertilizers is not economical as there is only two fold increase in yield on application of tenfold increased use of inorganic fertilizers (Bennet and Robinson, 1967). The organic carbon content is very low in tropical soil 
which is very important for soil organisms who contribute towards soil physical properties like aggregate stability, porosity, bulk density and water holding capacity. They also contribute towards immobilization as well as solubilization and mobilization of nutrients as and when required. Thus vermicompost which can be prepared without large scale investment can be utilized as an organic amendment to enhance biological process in soil. Thus primarily vermicompost can act as medicine for the health of soil and secondarily as a nutrient supplier to the crop.

Table.1 Nitrate Concentration in Ground Waters of Punjab and Haryana Exceeding 300 mg/l

\begin{tabular}{|l|l|l|l|l|}
\hline State & $\begin{array}{l}\text { No. of Sample } \\
\text { Analysed }\end{array}$ & Site & District & $\begin{array}{l}\text { Nitrate } \\
\text { Concentration (mg/l) }\end{array}$ \\
\hline Punjab & 1 & Sangrur & Sangrur & 362 \\
\hline & 1 & Bhatinda & Bhatinda & 567 \\
\hline & 1 & Hoshiarpur & Hoshiarpur & 435 \\
\hline Haryana & 1 & Ambala & Ambala & 990 \\
\hline & 2 & Faridabad & Faridabad & 560 \\
\hline & & Faridabad & Faridabad & 430 \\
\hline & 1 & Sirsa & Sirsa & 325 \\
\hline & 3 & Hisar & Hisar & 419 \\
\hline & & Hisar & Hisar & 363 \\
\hline & & Hisar & Hisar & 610 \\
\hline & 3 & Gurgaon & Gurgaon & 310 \\
\hline & & Gurgaon & Gurgaon & 450 \\
\hline & & Gurgaon & Gurgaon & 722 \\
\hline & 5 & Mahendergarh & Mahendergarh & 1310 \\
\hline & & Mahendergarh & Mahendergarh & 300 \\
\hline & & Mahendergarh & Mahendergarh & 393 \\
\hline & & Mahendergarh & Mahendergarh & 385 \\
\hline & & Mahendergarh & Mahendergarh & 830 \\
\hline
\end{tabular}

Source: Agriculture and Environment. Block 1. Environment: Agriculture Relationships. Pages 47-50. Indira Gandhi National Open University, School of Sciences. 2004

Table.2 Consumption of Fertilizers in India

\begin{tabular}{|l|l|l|l|l|l|l|l|}
\hline S. No & $\begin{array}{l}\text { Fertilizers Used } \\
\text { (lakh tones) }\end{array}$ & $1991-92$ & $2000-01$ & $2005-06$ & $2009-10$ & $2010-11$ & $2011-12$ \\
\hline 1 & Urea & 140.4 & 191.86 & 222.97 & 266.73 & 281.12 & 295.65 \\
\hline 2 & DAP & 45.18 & 58.84 & 67.64 & 104.92 & 108.70 & 101.91 \\
\hline 3 & MOP & 17.01 & 18.29 & 27.31 & 46.34 & 39.32 & 30.29 \\
\hline 4 & NPK Complex & 32.21 & 47.80 & 66.94 & 80.25 & 97.64 & 103.95 \\
\hline 5 & SSP & 31.65 & 28.60 & 7.56 & 26.51 & 38.25 & 47.46 \\
\hline
\end{tabular}

Source: State of Indian Agriculture (2012-13), GOI, Ministry of Agriculture, Department of 
Table.3 Bio-Pesticides Usage in the Country

\begin{tabular}{|l|l|l|}
\hline Sr.No. & Year & Bio-pesticides Consumption \\
\hline 1 & $2007-2008$ & 1873.00 \\
\hline 1 & $2008-2009$ & 1459.00 \\
\hline 2 & $2009-2010$ & 3366.00 \\
\hline 3 & $2010-2011$ & 5151.00 \\
\hline 4 & $2011-2012$ & 6506.00 \\
\hline \multicolumn{2}{|c|}{ Total 18355.00} \\
\hline
\end{tabular}

Sources: Directorate of Plant Protection, Quarantine and Storage

\section{Integrated Pest Management (IPM)}

The use of pesticides and insecticides is common practice to control pest and insects in modern agriculture. These chemicals not only kill the harmful and target organisms but also kill the non target as well as beneficial organisms e.g. population of honey bees is decreasing due to the use of these chemicals. Integrated Pest Management is an approach which control only harmful organisms leaving non target and beneficial organisms. Government of India had adopted IPM as a key principle of plant protection in 1985. Integrated Pest Management (IPM) is an eco-friendly approach which uses cultural, mechanical and biological tools and techniques for keeping pest population below economic threshold levels. However, need based and judicious use of chemical pesticides is permitted. With this objective, IPM helps in maximizing crop protection with minimum input costs, minimizing pollution in soil, water and air reducing occupational health hazards and reducing pesticide residue loads in food.

There are 31 Central Integrated Pest Management Centres (CIPMCs) located in 28 States and one Union Territory. CIPMCs undertake following activities:-

1. Surveillance and monitoring of insect pests and diseases.

2. Augmentation and conservation of natural enemies.

3. Production and releases of bio-control agents.

4. Human resources development through Farmers Field Schools (FFSs) for training.

Actually IPM is a practice to control diseases and pests by cultivation, chemicals and biological methods. It is based on the experience and traditional knowledge of the farmers. The natural predators of the different types of pests are identified and used to control the pests e.g. birds. Hormones are also used that interrupt the pest normal life cycle, thereby preventing it from attainment of maturity and reproducing and multiplying. The farmers continuously keep an eye on the crops and when they observe that the population of pest to be high, they immediately use the biological methods and cultivation practices to control the pest and then use the small amount of insecticide derived from plants extracts known as bio-pesticides. Botanical pesticides such as those derived from Neem could be used. Selective microbial pesticides offer particular promise, of which strains of Bacillis thuringiensis is an example. Table: 3 depict the consumption pattern of biopesticides in the country.

\section{Use of Genetic Engineering and Biotechnology}

Agricultural biotechnology and genetic 
engineering may play important role for second "Green Revolution". The different crop cultivars developed by the use of 'Genetic Engineering' are resistant to disease \& pest attack, tolerant to drought, having better aroma \& flavor, grow in salt affected \& water logged soil and better nutritional value. The crop cultivars developed such as are known as genetically modified (GM) plants. Some important examples of GM crops are:

- 'BT Cotton' produced by incorporation of $\mathrm{Bt}$ gene from bacteria (Bacilus thuringinesis) making cotton plant resistant to pest namely American boll worm.

- 'Golden Rice' is a genetically modified rice cultivar rich in Vitamin A, tolerant to salt, resistant to pesticides and having high yield.

GM crops lot of benefits e.g. good taste \& quality, increased yield \& nutrients, resistant to pest \& diseases, stress tolerant, safe for environment \& society but also have some drawbacks e. g. effecting biodiversity, unknown effects on other living beings, may contaminate soil, influence of MNC on developing countries, violation of intellectual property rights, tampering with nature etc.

In conclusion, there is no doubt that 'Green Revolution' make India self dependent in term of food grains but indiscriminate use of synthetic fertilizers and pesticides contaminated our food and environment. Punjab, a small state of Indian Republic known as grain bowl of the country is facing serious problems. Groundwater depletion, nutrient imbalance in the soil, groundwater and surface water contamination, pesticide residues in food and bovine milk and increasing cancer rate in farmers are some of the example of 'Green Revolution'. Due to these reasons people are demanding second 'Green Revolution' which not only provide healthy food but also take care of the nature. Earlier farmers used to grow traditional crop cultivars which require fewer amounts of nutrients, pesticides and irrigation water. Due to non availability of canal and tubewell water for irrigation they grow one or two crops annually and due to these soils replenish nutrients naturally. In modern agricultural farmers used to two to three crops in a year which require huge amount of nutrient, pesticides and these practices create a lot of human and environmental health problems. Therefore, traditional agricultural practices can play an important role for sustainable agriculture. Hence, keeping in mind the problem created by modern agriculture to fulfill the food requirement of humanity traditional and sustainable agriculture is a solution which provides us organic food which is healthy, nutritious and tasty.

\section{References}

Arora, P. 2007. "Pesticide and Human Health", A Resource for Health Professionals, 4 (1 - 2): 7-9.

Grace C, V. Muraleedharan; T. Swami Nathan and D. Ranghhavi. 2007. Use of Pesticides and its Impact on Human Health: A Case of Farmers in South Asia, Madras, Indian Institute of

Gupta, P. 2004, "Pesticide Exposure Indian Scene", Journal of Technology, 198 (83): $118-119$.

Hashmi, Imran and Khan A. Dilshad 2011. Adverse Health Effects of Pesticides Exposure in Agricultural and Industrial Workers of Developing Country, Pesticides - The Impacts of Pesticides Exposure, Prof. Margarita Stoytcheva (Ed.), ISBN: 978-953-307-531-0.

Jeyaratnam, J. 1990. Acute pesticide 
poisoning: A major global health problem. World Health Statistic Quarterly. 43., 3., 139-44.

Kishi, M.; Hirschhorn, N.; Ojajadisastra, M.; Satterfee, L.N.; Stroman, S. \& Dilts, R. 1995. Relationship of pesticide spraying to signs and symptom in Indonesian farmers. Scand. J. Environ. Health., 21.,124-33.

McCauley, A.; Linda, Anger, K.W.; Keifer, M.; Langley, R. \& Robson, G.M. 2006. Studying health outcomes in farm worker populations exposed to pesticide. Environ. Health. Perspec., 114, 6-8.

Pimental, D., Acguay, H. and Biltonen, M. 1992. Environmental and economic costs of pesticide use. Biosci., 42. : $750-60$

Takagi, K, Kazuhiro, O, Lleji $\mathrm{M}$ and Masako, A. 1997. "Use Research and Development of Pesticides in Relationship to Sustainable Agriculture in Japan," Japan Agricultural Research Quarterly, 31 (2): 13- 20.

WHO 1985. Health hazards from nitrate in drinking-water (pp. 1-102). Report on a WHO meeting, Copenhagen, 5-9 March 1984. Copenhagen, WHO Regional Office for Europe. Environmental Health Series No. 1.

\section{How to cite this article:}

Bhupinder Singh and Lalit Jajpura. 2016. Sustainable Agriculture: A Key to the Healthy Food and Better Environment, Economic Prosperity for Farmers and a Step towards Sustainable Development. Int.J.Curr.Microbiol.App.Sci. 5(1): 148-156. doi:'inttp:///dx.doi.org/10.20546/ijcmas.2016.501.012 